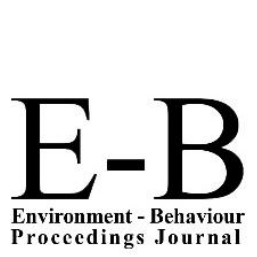

\author{
ASLI QoL 2017 \\ AQoL2017Kuching \\ http://www.amerabra.org; https://fspu.uitm.edu.my/cebs \\ $3^{\text {rd }}$ ABRA International Conference on Quality of Life \\ "Quality of Life 3"
}

Riverside Majestic Hotel, Kuching, Malaysia, 14-16 Oct 2017

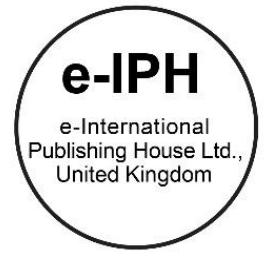

\title{
People in City: The relation of urban park and the quality of life
}

\author{
Hazlina Hamdan, Nurul Shakila Khalid, Nurul Faizah Baba \\ Centre of Studies for Town and Regional Planning, Faculty of Architecture, Planning and Surveying, \\ Universiti Teknologi MARA Selangor, Kampus Puncak Alam, Puncak Alam, 42300 Malaysia. \\ Hazlina594@salam.uitm.edu.my \\ Tel: $+6012-7381457$
}

\begin{abstract}
Well-designed of an urban park is one of the best ways to achieve the city sustainable development and contributes to the quality of life in many ways. Central to this argument is the claim that the variables need to be considered and thus, this research was conducted to assess the quality of urban park by empirically evaluating through behavioral competencies and psychological well-being from the model of Lawton's Quality of Life. A quantitative research method was employed for the research with 138 respondents in Taman Lembah Bukit SUK, Shah Alam. Results confirm that the urban park provides the potential for psychological well-being, but it often underutilized and attract the aged of 19-50 years old of a user group.
\end{abstract}

Keywords: Quality of Life; Urban Park; Behavioral Competencies; Psychological Well-being.

eISSN: 2398-4287@ 2017. The Authors. Published for AMER ABRA by e-International Publishing House, Ltd., UK. This is an open access article under the CC BYNCND license (http://creativecommons.org/licenses/by-nc-nd/4.0/). Peer-review under responsibility of AMER (Association of Malaysian Environment-Behaviour Researchers), ABRA (Association of Behavioural Researchers on Asians) and cE-Bs (Centre for Environment-Behaviour Studies), Faculty of Architecture, Planning \& Surveying, Universiti Teknologi MARA, Malaysia.

https://doi.org/10.21834/e-bpj.v2i6.996

\subsection{Introduction}

Cities are a huge deal especially when they have become the residence for many populations and offer necessities to most world's population for ages. At the broadest level, the well-design and planning of urban park play a vital role in improving quality of life among urban community particularly to improve health status, improving the general living environment and fulfill total life satisfaction. The presence of parks in the urban setting is not only for the human well-being but importantly for the city's well-being. According to Chiesura (2004), urban nature places prominent importance in contributing to city sustainability through improving the well-being of its inhabitant. Existing leisure research has confirmed that various recreational activities could indeed generate short-term benefits including positive mood, physical fitness, and immediate satisfaction, as well as long-term effects of enhancing happiness, mental health, physical health and social interaction (Lu, 2011).

Urban park or as in general refer to open space is defined as a public area that is used for recreational purposes without being charged with any fees and open for the public to assess every day (Department of Town and Regional Planning, 2000). Ulrich and Addoms (1981) found that people gain benefits of psychological including a feeling of open space, change of scenery and a place to escape their busy lives. In addition, More and Payne (1978) identified that the park users are reported to have the lower level of anxiety and reduce their sadness after visiting the park. While Teal et al., (1998) mention that there is a correlation between stresses, the chronical problem of urban poor with the quality of the environment. Bakar et al., (2016) notes that the use of leisure time in the park for recreational activity is good from the perspective of psychosocial, health and well-being of urban residents particularly.

However, we found that having controlled for effects of demographics, physical health, social interaction (read: social support), and positive leisure experiences were negatively related to indicators of well-being in urban area. An underlying spirit of the study,

eISSN: 2398-4287C 2017. The Authors. Published for AMER ABRA by e-International Publishing House, Ltd., UK. This is an open access article under the CC BYNCND license (http://creativecommons.org/licenses/by-nc-nd/4.0/). Peer-review under responsibility of AMER (Association of Malaysian Environment-Behaviour Researchers), ABRA (Association of Behavioural Researchers on Asians) and cE-Bs (Centre for Environment-Behaviour Studies), Faculty of Architecture, Planning \& Surveying, Universiti Teknologi MARA, Malaysia.

https://doi.org/10.21834/e-bpj.v2i6.996 
thus, is to extend the current literature on the subject by exploring of how urban community can improve their long-term quality of life in the urban context of Shah Alam through the higher participation of recreational activity in the urban park. The study focuses on the fundamental mission: what attributes of such paces are relevant to QoL for better using of park among inhabitants for enhanced quality of life. For this reason, QoL measures the psychological health, social behavior, social interaction and the level of satisfaction with aspects of the urban park that associated with health, life satisfaction, and recreational activity.

\subsection{Literature Review}

\subsection{Urban People's Quality of Life}

The quality of life is deliberated as a development realm and plays a vital role in individual satisfaction (Leitmann, 1999). Quality of life or what is generally referred to as QoL is a multifaceted concept that embraces not only material aspects of life such as level of living, availability of physical and social infrastructural facilities but also the less tangible aspects of life include good health and opportunities for recreation (Kaplan and Kaplan, 1989).

In Malaysia, The Economic Planning Unit (EPU) in its report on the Malaysian Quality of Life Index 2002, defines quality of life as encompassing personal advances, a healthy lifestyle, access and freedom to pursue education, and attaining a standard of living which surpasses the fulfillment of the basic and psychological needs of the individual, to achieve a level of social well-being compatible with the nation's aspirations (EPU, 1999). As stated in Malaysia Quality of Life Index, the QoL is determined by 12 components and over 29 indicators as a tool to measure the quality of life in Malaysia as shown in Table 1. The indicators were chosen by their significance and the availability of data on a time series basis and were assigned equal weightage. However, the focus on the provision of the good design and quality of urban park still lacking despite having the related index on health, social participation, and recreational and culture components. Obviously, the provision of open space and recreational area is only to fulfill the $10 \%$ open space requirement applied in every housing scheme without considering the quality in the built environment.

Table 1. The Components of Malaysian Quality of Life Index (MQLLI)

\begin{tabular}{|c|c|}
\hline Components & Indicators \\
\hline Income and Distribution & $\begin{array}{ll}- & \text { Real per capita income } \\
\text { - } & \text { Incidence of poverty } \\
\end{array}$ \\
\hline Working Life & $\begin{array}{ll}\text { - } & \text { Unemployment rate } \\
\text { - } & \text { Gender equality in labour workforce } \\
\text { - } & \text { Industrial accident rate } \\
\end{array}$ \\
\hline Transport and Communications & $\begin{array}{ll}\text { - } & \text { Private motorcars and motorcycles } \\
\text { - } & \text { Telephones } \\
\text { - } & \text { Internet subscribers } \\
\end{array}$ \\
\hline Health & $\begin{array}{ll}\text { - } & \text { Doctors population ratio } \\
\text { - } & \text { Infant mortality rate } \\
\text { - } & \text { Maternal mortality rate } \\
\end{array}$ \\
\hline Education & $\begin{array}{ll}\text { - } & \text { Literacy rate } \\
\text { - } & \text { Pre-school participation rate } \\
\text { - } & \text { Tertiary Participation rate } \\
\text { - } & \text { Graduate teachers } \\
\text { - } & \text { Secondary and secondary school teacher-student ratio } \\
\end{array}$ \\
\hline Housing & $\begin{array}{ll}\text { - } & \text { Low-cost housing units } \\
\text { - } & \text { Average rental to household income ratio } \\
\text { - } & \text { Average prices of houses to household income ratio }\end{array}$ \\
\hline Environment & $\begin{array}{ll} & \text { Air quality } \\
\text { - } & \text { Water quality } \\
\text { - } & \text { Forested land }\end{array}$ \\
\hline Family Life & $\begin{array}{ll}\text { - } & \text { Divorces } \\
\text { - } & \text { Household size } \\
\text { - } & \text { Juvenile crimes } \\
\text { - } & \text { Average household income } \\
\end{array}$ \\
\hline Social Participation & $\begin{array}{ll}\text { - } & \text { Rukun Tetangga Members } \\
\text { - } & \text { Registered voters } \\
\text { - } & \text { Registered Voluntary Organizations } \\
\end{array}$ \\
\hline Public Safety & $\begin{array}{ll}- & \text { Crimes } \\
\text { - } & \text { Road accidents } \\
\end{array}$ \\
\hline Urban Services & $\begin{array}{ll}- & \text { Expenditure on landscaping } \\
\text { - } & \text { Expenditure on social services } \\
\end{array}$ \\
\hline Recreational and Culture & $\begin{array}{ll}\text { - } & \text { Membership in public library } \\
\text { - } & \text { TV viewers } \\
\text { - } & \text { Community planning } \\
\text { - } & \text { Organizational activities } \\
\end{array}$ \\
\hline
\end{tabular}


Additional to the issues, dissatisfaction with the current urban living condition and many of other associated issues can be identified to the insufficient of a city to meet the basic need of its inhabitants. One of the fundamental components of the people's quality of life is the feasibility of recreational opportunities as a basis for creating a sustainable community.

\subsection{Parks and Quality of Life}

Design and planning of parks can make a difference. In fact, the body of evidence in both the natural and built environments suggests that inspired design can make a significant improvement in the quality of life (Bakar et al., 2016). According to Teal et al., (1998), the design, planning, and management of parks are vital to achieving sustainable urban park. In order to achieve the sustainable development goal, it is important to follow the dimensions of the sustainability city; environmental, social and economic. These three (3) dimensions should be balanced to form a harmonious human-nature relationship. Aware of this insight, the park is one of the best ways to develop the sustainable community as well as it, directly and indirectly, improving the quality of life of the urban community.

Accordingly, Malaysia has implemented the open space and recreation policy and guidelines such as the Malaysia Guideline and Planning Standard for Open Space and Recreation, regardless of socio-economic status. Recreational areas in a neighborhood that functional for recreation, sports, and social activities, as it can be seen in present residential development. Hence, it is important to note that, based on the population size in the study areas, the use of "urban park" in the study is to represent the green open spaces provided in residential development (includes several neighborhood areas) that provided for recreation and social activity. According to the planning standard and guidelines, an urban park can be defined as a recreational area provided for urban residents in the area of 40 hectares to cater 50,000 people and above.

Many researchers found that recreational activities in the park can influence health through complex and interconnected biopsychosocial mechanism. In addition, it can be used as a diversion medium to divert the psychological distress into enjoyment phase. There is a large volume of recent studies explaining the benefits of recreational activities participation such as reduce loneliness, improving health status, improve positive mood, increase life satisfaction and promote psychological well-being (Sajin et al., 2016). As Lu (2011) in his research to 1,143 young people in Taiwan found that the young people who actively engage in recreational activities have a negative relationship with depression. Similar to the study conducted by Dergance et al. (2003) describes that enjoyment in the participation of recreational activity, improve health status, give chance to meet new people and reduce depression.

By referring the findings, Lawton (1991) conceptualized the quality of life model through four (4) components include behavioral competencies, perceived quality of life, the objective environment and psychological well-being. For this study, its only give focus on the behavioral competencies and psychological well-being. In details, behavioral competencies refer to the social-normative assessment of an individual health, cognition, and social relationship. For psychological well-being, it refers to the cognitive life satisfaction and emotional well-being (positive or negative emotions). These two (2) components were chosen because they are much related to the physical activity that people did in the park and the benefits of doing recreational activity in improving their health status, social interaction with other visitors, and give satisfaction in life. Additionally, these have consequences for the model of QoL and referring as major aspects of the quality of life (Lawton, 1991) with competence, social relations, and environmental support.

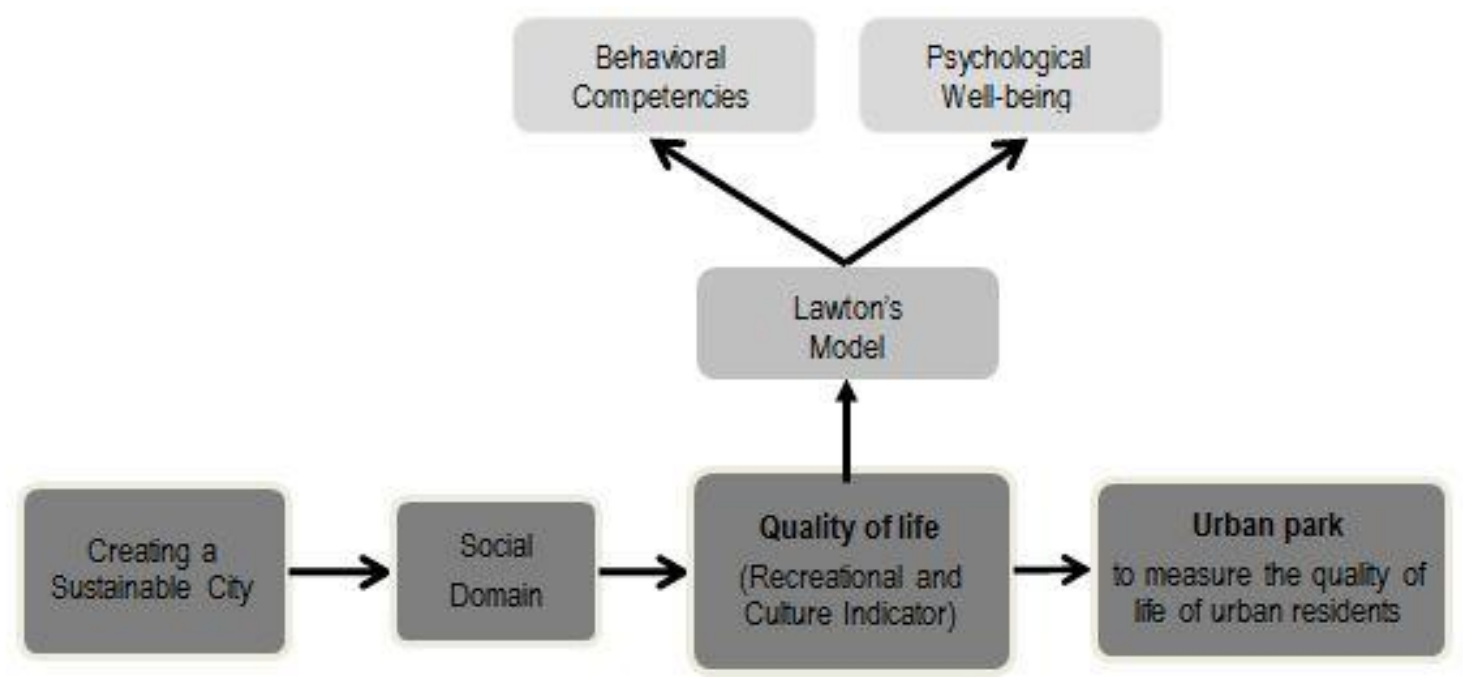

Fig. 1: Lawton's Quality of Life Model

According to Silverstein and Parker (2002), when the individuals engage in the recreational activities, it can contribute to the positive outcome especially in aspects of mood and emotion since emotions of comfort may interpret as responses to environmental qualities. Moreover, Lawton (1991) in the study of community-dwelling elderly people found that higher level of participation in especially in social relationship and cognitive activities can contribute to better Health-related Quality of Life (HrQOL). As health is one of the aspects included in the Behavioral Risk Factor Surveillance System, to monitor people's health status. So, too, the World 
Health Organization (WHO) has since 1948 defined health as a state of complete physical, mental and social well-being and not merely absence of disease or infirmity.

This study thus was supported by Sajin et al., (2016) found that higher recreational activity participation, without doubt, has a significant relationship with each other and improves cognitive function. Another potential relationship between park and QoL also include social interaction or social activity, which may take place in such neighborhood settings. A recent research of older people in Sweden has shown that the availability of open spaces nearby predicted the strength of ties among residents. At the very basic level, the use of outdoor common spaces like urban park increases the social interactions among residents and can contribute to the sense of community, to avoid people for being an individualistic live in the urban area (Dergance et al., 2003).

\subsection{Methodology}

\subsection{Data Collection and Research Design}

Methodologically, quantitative research methods were used as the method of study to identify the benefits of participation in the recreational activity in the urban park. Using semi-structured questionnaire, the survey focused on the holistic experience of life rather than on actual conditions of life through the variable based on psychological health, social behavior, level of satisfaction of on aspects of the urban park, and social interaction. The survey covers four (4) parts include Part A: Respondents' Profile, Part B: Visitor Behavior (Likert-scaled questions), Part C: Psychological Well-being, and Part D: Respondents' Perception. A total of 134 questionnaires were distributed randomly to the visitor in Tasik Lembah Bukit SUK. Notably, Part B: Visitor Behavior, the researcher evaluate the social interaction among the visitors that much related to the component of behavioral competencies. While Part C: Psychological well-being, the respondents were asked about the emotions of happiness and comfort that later be interpreted as feelings of psychological wellbeing. Furthermore, the visitors' emotion (read: positive emotion) may affect their everyday life satisfaction (Lawton, 1991) especially in active involvement to achieving psycho-social well-being.

By using a 1-5 scale of satisfactory, the results of each variable converted into percentage from overall mean and standard deviation. The numbers were also divided by gender in conjunction to raise the comparison result between both male and female quality of life. To ensure the trustworthiness of the study, several methods were employed such as no bias was ensured during the construction of open-ended questions and questions from the pilot study were used in the actual study for every each of respondent.

\subsection{Study area}

The study was carried out in Taman Lembah Bukit SUK, Section 5, Shah Alam, with the total area is 29 hectares. Developed to be a self-contained neighborhood, it was created by the state of Selangor in 1978 after the declaration of Shah Alam as the new Selangor state capital. The park can be accessed via Jalan Pegawai and located near to the government institutions such as MAIS, Justice Complex, Building of Sultan Salahuddin Abdul Aziz Shah, royal tombs and state monument. Taman Lembah Bukit SUK was provided to cater the recreational needs from nearby residences in Section 5, 6, 9 and 11. Additionally, the park thus becomes an important element in helping the residential area create a desirable gathering space for its residents, other than just to fulfill the planning approval requirements in housing scheme development.

In Taman Lembah Bukit SUK, there are several recreational facilities such as lookout tower, bench, gazebo, man-made lake, jogging track, vehicles parking, children's playground, grassy areas, and $4.2 \mathrm{~km}$ pedestrian walkway.

The provision of this urban park is incorporated in the planning guidelines of open used by Shah Alam City Council which considered the population size; 50,000 people to cover the total population in Shah Alam - 185,585 people. Figure 2 shows the location of Taman Lembah Bukit SUK in Section 5, Shah Alam.

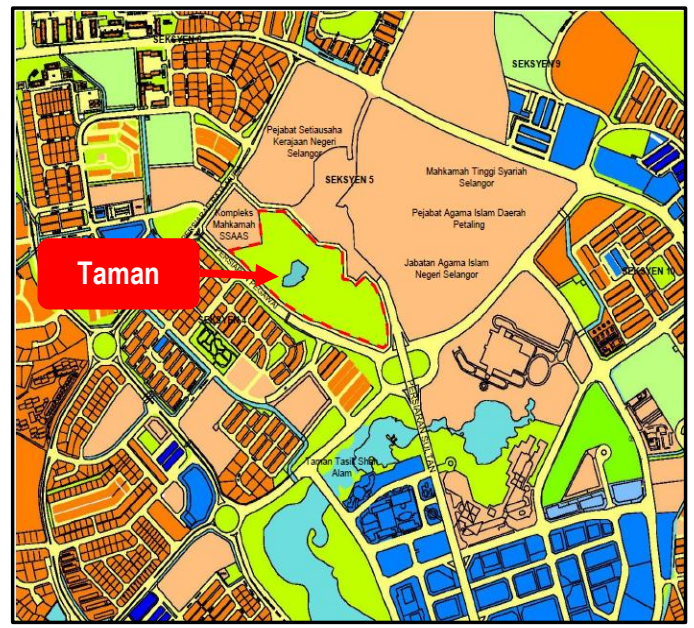

Fig. 2: The location of Taman Lembah Bukit SUK Shah Alam (Source: Planning Department, MBSA, 2014). 
The selection criteria of Taman Lembah Bukit SUK Shah Alam were based on several aspects. Frist, Shah Alam is selected to be the geographical location as it is identified as the most urbanizing area in Selangor. Second, the size of Taman Lembah Bukit SUK approximately is 40 hectares and the population size range is 185,585 residents.
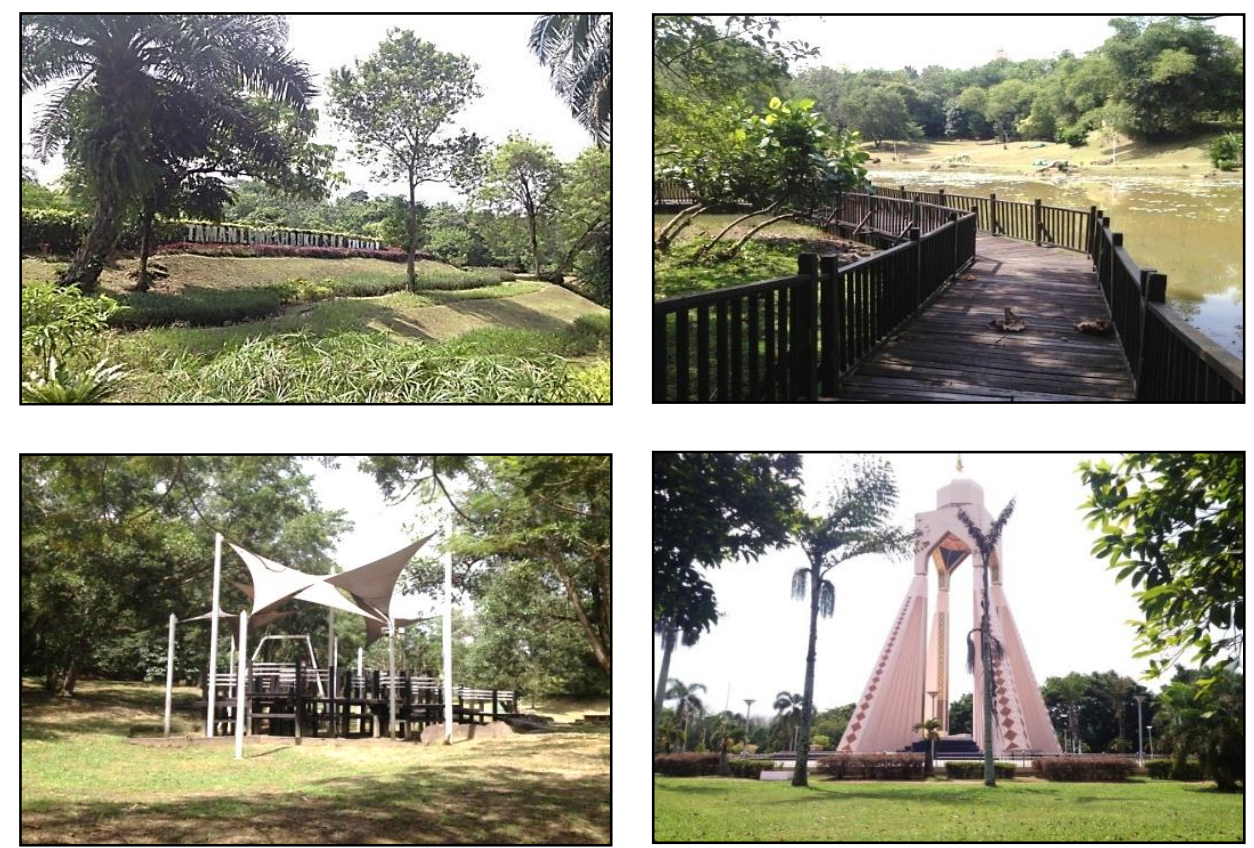

Fig. 3: Recreational facilities in Taman Lembah Bukit SUK Shah Alam. (Source: Author, 2017)

\subsection{Results and Discussion}

\subsection{Respondents' Profile}

The respondents in this study were the park users who are the residents of the nearest neighbourhood; Section 5, 6, 9 and 11. The total respondents in this study were 134 park users who came to the park either every day or weekend - in the morning (between 7 $10 \mathrm{am}$ ). The recreational participation in this study can be explained based on several demographic characteristics including sex, age group, ethnicity, and occupation (see Table 3) were assessed as potential confounding variables.

Table 3. Demographics characteristic of respondents

\begin{tabular}{llll}
\hline Respondents' Profile & Details & $\mathrm{N}=134$ & $\%$ \\
\hline Sex & Male & 66 & 49.2 \\
Age Group & Female & 68 & 50.8 \\
& $12-18$ years old & 4 & 5.2 \\
& $19-24$ years old & 50 & 33.5 \\
& $25-30$ years old & 52 & 32.0 \\
Marital Status & $31-50$ years old & 21 & 17.3 \\
Ethnicity & 51 years old and above & 7 & 12.0 \\
& Single & 70 & 52 \\
Occupation & Married & 64 & 48 \\
& Malay & 79 & 59 \\
& Chinese & 47 & 35 \\
& Indians & 8 & 6 \\
& Professional & 11 & 8.2 \\
& Government & 20 & 15.3 \\
& Private & 25 & 18.7 \\
& Self-employed & 16 & 12.0 \\
& Pensioner & 5 & 3.8 \\
& Student & 53 & 39.0 \\
\hline
\end{tabular}

Analysis of participation among age group shows that adults between 19 to 50 years old consistently exhibited higher participation rates in the park. The mean age of the sample was 25 to 35 years old and $39.0 \%$ of the respondents were the student who actively participates in recreational activity given that the study area is near to UiTM and others college and school. 
The recreational preference differed by gender. In overall, the respondents are balanced between male and female respectively 66 $(49.2 \%)$ and 68 (50.8\%). The cross-sectional analysis between gender, age and occupation show that women of age 19 to 50 years old resulted 68 of the total respondents with $60 \%$ of them are married and $65 \%$ are working women (both working in government and private sector). The type of occupation and marital status shows the strong relationship that describes the factor that may contribute to the higher participation of woman in recreation activity in the park. However, the results of male participation almost balance. This also suggests that both male and female today really aware the benefits of recreational activity and practice the healthy lifestyle. Additionally, this finding suggests that both male and female have equality in recreation opportunity.

\subsection{Quality of Life Analysis}

Results of the study focus on the quality of life index among the visitors in Taman Lembah Bukit SUK in this marginalized according to descriptive analysis. Table 4 reports the quality of life index for the 134 samples (n-134). Chi-square was used to the test the significant relationship between behavioral competencies and psychological well-being and the five (5) variables; social interaction, physical activity, health status, level of satisfaction, and respondents' emotion.

Relationship between visitation to park and behavioural competencies.

Relationship between visitation to park and psychological well-being.
$=$ To measure the level of social interaction among visitors and health status.

= To measure the level of satisfaction on recreational facilities and respondents' emotion.

Table 4. Results of Chi-square of behavioral competencies and psychological well-being and recreation participation

\begin{tabular}{lccccc}
\hline & \multicolumn{2}{c}{ Age Group } & & \\
\hline Quality of Life Attributes & & & $p$-value \\
& $12-18$ & $19-24$ & $25-30$ & $31-50$ & 51 and above \\
\hline Behavioral Competencies & & & 0.001 & 0.045 & 0.049 \\
Social interaction & 0.031 & 0.001 & 0.002 & 0.003 & 0.055 \\
Health & 0.049 & 0.002 & 0.001 & 0.001 & 0.001 \\
$\begin{array}{l}\text { Physical activity } \\
\text { Psychological well-being }\end{array}$ & 0.021 & 0.034 & 0.008 & 0.003 & 0.016 \\
Level of satisfaction & 0.022 & 0.004 & 0.448 & 0.526 & 0.016 \\
Emotion & 0.022 & 0.016 & & & \\
\hline
\end{tabular}

Significant level at $p<0.05$

According to the results in Table 4, the attributes of physical activity, $x^{2}(1)=0.001, p=0.010>0.05$ shows no relationship between visitation and physical activity. After examining the relationship between recreation participation and physical activity, each age group was isolated and examined independently of the other especially age between 25 to 30 years old. Here, the physical activity includes daily routine, active and passive activity. Most of the respondents at the age of 31-50 years old, they prefer to enjoy walking in the park compared to the age group of 19 to 30 years old which is they prefer to jog, play a football, and cycling. More significantly, the results were used to determine whether further analyses investigating the differences of age group. The concern lies in the fact that at the age of 19 to 50 years old, most of them are heavily engaged in study, work and family relationships, and this involvement may contribute to their levels of positive affect and fulfillment as well as their levels of distress.

As part of the study, health and recreation are interrelated and components of QoL. Respondents' health status was measured as the number of days in the last 30 days in which poor physical and/or mental health prevented them from carrying out the daily routine and recreational activity. Whereas health is a consideration, the result should not neglect the long-term well-being of the urban inhabitants which has a lot more to do with psychologically. Participants reported on average 7 days of unhealthy days in the last 30 days and their mean frequency of visit score was 3.5 in the range between 1 and 5 . The level of individual health may be influenced by other factors such as dieting menu and lifestyle. However, participation in the recreational activity in the park is one way to have life satisfaction and healthy lifestyle especially live in a densely populated city.

\subsection{Respondents' Satisfaction of the Aspects of Urban Park}

The aim of the quality analysis was to gather from the visitors about the quality of the urban parks. This study used present assessment tool name quality neighborhood parks criteria (QNPC) developed by researcher and practitioner in the field of landscape architecture, parks, and recreation (Abdul Malek et al., 2011). The objectives of developing this quality tool are to understand the users' needs and to help park designers and managers to develop and manage parks. QNPC was developed based on user preferences, needs, use pattern and overall satisfaction among the visitors. It is important to focus on enhancing the quality of open spaces, including their natural features and the provision for social interaction (Abdul Malek et al., 2011). For this study, only six (6) criterion of park quality was chosen to evaluate the resident's overall satisfaction on the quality of the park in aspects of location, safety, recreational facilities, landscape elements, activities, and management and maintenance of the park as stated in Table 5. Each 
of the criteria was resulted based on the level of importance which is scored as very poor (1), poor (2), fair (3), good (4) and very good (5).

Table 5. Level of Overall Visitor's Satisfaction on Parks Criteria.

\begin{tabular}{|c|c|c|c|c|c|c|}
\hline Grading Scale & Location & Safety & Recreational Facilities & $\begin{array}{l}\text { Landscape } \\
\text { Elements }\end{array}$ & Activities & Maintenance and Management \\
\hline Very Poor & 14 & 10 & 8 & 7 & 7 & 20 \\
\hline Poor & 21 & 39 & 22 & 19 & 28 & 34 \\
\hline Fair & 37 & 25 & 55 & 57 & 61 & 47 \\
\hline Good & 53 & 43 & 45 & 44 & 33 & 30 \\
\hline Very Good & 9 & 17 & 4 & 7 & 5 & 3 \\
\hline Mean & 3.16 & 3.12 & 3.34 & 3.19 & 3.21 & 2.72 \\
\hline Std Deviation & 0.976 & 0.956 & 0.923 & 0.927 & 0.905 & 1.045 \\
\hline
\end{tabular}

From the table above, the results are based on the Likert Scale and it shows that all the criteria scored as fair. It suggests that the respondents satisfied with the park criterion provided in the park. Overall, the highest mean scores were recreational facilities and activities while the lowest mean score was maintenance and management aspects.

\subsection{Conclusion}

This study has added to our understanding of the ways in which urban living environments are associated with its inhabitants' quality of life. Hence, the purposes of the park are not only to strengthen the strong social relationship among the urban community, but the status of health is important to discuss in improving the quality of life of urban residents and sustainability of the city itself. Overall, the quality of parks was found relevant to peoples' life satisfaction, whereas the quality of health, physical activity was correlated with the level of happiness and satisfaction, regardless of respondents' age, sex, occupation, ethnicity, and marital status. The success of a park needs consideration of several criteria as revealed in this study; location, safety, recreational facilities, landscape elements, activities, and maintenance and management.

Growing concerns over the provision of the urban park as studies on quality of life among urban resident importantly point to the importance of the benefits of participating in the recreational activity to achieve life satisfaction and to be more sensitive to the social implications of any physical design and planning. The effectiveness of quality aspects of the park must be given decent attention especially sufficient for all age groups as to improve quality of life among park users'. Interestingly, much previous research from many theoretical perspectives has identified the importance of recreation to humans. Thus far, in present-day urban environments where almost every aspect of human life is changing at accelerating rate, and recreation by way of contrast to the concentrated, hectic, and the high speed of work are extremely valuable to the urban residence. The opportunities for recreation are, therefore, a prominent focus for investigation, particularly in rapidly, urbanizing, highly time and space compressed societies such as Shah Alam where available opportunities have been transformed as higher-density development progress.

Future research should explore the importance of health by taking consideration the outdoor activity (walking), whereas the quality of pathway to park was associated with walking behavior. As an example, the amount of walking can be objectively measured with a pedometer or accelerometer. Or, Geographic Information Systems may be employed to measure the degree of walkability by each group of park users (from the age of 18 to 50 years old) of a neighborhood based on its physical properties. On a larger canvas, the future research may investigate the role of environmental interventions such as shared space streets on people's activity patterns and their well-being. In recent research, environmental interventions can promote people's health, well-being, and active lifestyle, and help to develop policies to improve neighborhood environment for community particularly.

\section{References}

Abdul Malek, N., Mariapan, M., Kamal, M., \& Shariff. (2011). Assessing the Needs for Quality Neighbourhood Parks. Australian Journal of Basic and Applied Sciences, $5(10), 743-753$.

Bakar, N. A., Malek, N. A., \& Mansor, M. (2016). Access to Parks and Recreational Opportunities in Urban Low-income Neighbourhood. Procedia-Social and Behavioral Sciences, 234, 299-308.

Campbell, A., Converse, P. E., \& Rodgers, W. L. (1976). The Quality of American Life: Perceptions, Evaluations, and Satisfactions. New York, Russell Sage Foundation.

Chiesura, A. (2004). The Role of Urban Parks for the Sustainable City. Landscape and Urban Planning, 68(1), 129-138.

Conway, H. (2000). Parks and People: The Social Functions. The Regeneration of Public Parks, 9-20.

Dergance, J. M., Calmbach, W. L., Dhanda, R., Miles, T. P., Hazuda, H. P., \& Mouton, C. P. (2003). Barriers to and Benefits of Leisure Time Physical Activity in the Elderly: Differences Across Cultures. Journal of the American Geriatrics Society, 51(6), 863-868.

Guidelines and Planning Standard for Open Space and Recreation (2000). Department of Town and Country Planning, Peninsular Malaysia. 
Kaplan, R., \& Kaplan, S., (1989). Experience of Nature: A Psychological Perspective. Cambridge University Press, New York.

Lawton, M. P. (1991). A Multidimensional View of Quality of Life in Frail Elders. The Concept and Measurement of Quality of Life in the Frail Elderly, 3-27.

Leitmann, J. (1999). Can City QOL Indicators be Objective and Relevant? Towards a Tool for a Sustaining Urban Development. Local Environment, 4(2), 169-180.

Lu, L. (2011). Leisure and Depression in Midlife: A Taiwanese National Survey of Middle-aged Adults. Journal of Health Psychology, 16(1), 137-147.

More, T. A., \& Payne, B. R. (1978). Affective Responses to Natural Areas near Cities. Journal of Leisure Research, 10(1), 7-12.

Omar, K. A., Omar, D., Othman, S., \& Yusoff, Z. M. (2017). Youth in Public Housing: Place attachment and Quality of Life Index. Environment-Behaviour Proceedings Journal, 2(5), 325-332.

Sajin, N. B., Dahlan, A., \& Ibrahim, S. A. S. (2016). Quality of Life and Leisure Participation amongst Malay Older People in the Institution. Procedia-Social and Behavioral Sciences, 234, 83-89.

Silverstein, M., \& Parker, M. G. (2002). Leisure Activities and Quality of Life among the Oldest Old in Sweden. Research on Aging, 24(5), 528-547.

Teal, M., Huang, C. S., \& Rodiek, J. (1998). Open Space Planning for Travis Country, Austin, Texas: A Collaborative Design. Landscape and Urban Planning, 42(2), 259-268.

Ulrich, R. S., \& Addoms, D. L., (1981). Psychological and Recreational Benefits of a Residential Park. Journal of Leisure Research, $13(1), 43$. 